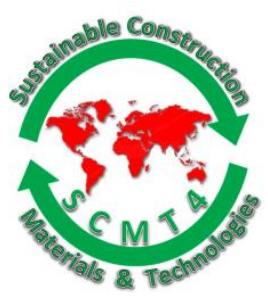

SCMT4

Las Vegas, USA, August 7-11, 2016

\title{
Drying Shrinkage of Alkali Activated Fly Ash: Effect of Activator Composition and Ambient Relative Humidity
}

\author{
Maryam Hojati ${ }^{1 a}$, Farshad Rajabipour ${ }^{1 b}$, and Aleksandra Radlińska ${ }^{1 \mathrm{c}}$ \\ ${ }^{I}$ Department of Civil and Environmental Engineering, The Pennsylvania State University, University \\ Park, PA 16802, USA. \\ ${ }^{1 a}$ Email: <hojati.maryam@gmail.com>; ${ }^{1 b}$ Email: 〈Farshad@psu.edu>; ${ }^{1 c}$ Email: 〈ara@engr.psu.edu>.
}

\begin{abstract}
Alkali activated fly ash (AAFA) is an alternative concrete binder that could serve as a substitute for ordinary Portland cement (OPC) for certain engineering applications. While this material has significant environmental and durability benefits, its potential volume instability and propensity to shrinkage and cracking could be of great concern. The subject of the present paper is evaluating the magnitude of drying shrinkage in AAFA binders of different compositions and at various ambient relative humidities (RH). Four AAFA paste mixtures were prepared using class $\mathrm{F}$ fly ash and liquid sodium silicate activators with various alkalinity $(\mathrm{pH})$ and silicate modulus $\left(\mathrm{n}=\left(\mathrm{SiO}_{2} / \mathrm{Na}_{2} \mathrm{O}\right)_{\text {molar }}\right)$. The results were also compared with an OPC paste with a similar initial porosity. All AAFA pastes were steam cured at $60^{\circ} \mathrm{C}$ for 24 hours, followed by 6 days of moist curing at $23^{\circ} \mathrm{C}$, while the OPC specimens were moist cured at $23^{\circ} \mathrm{C}$ for 7 days. The shrinkage specimens were dried under nitrogen purge at different relative humidities. The results show that activators with intermediate $\mathrm{pH}$ and modulus led to AAFA binders with higher compressive strength, denser pore structure, and larger drying shrinkage. Regardless of the activating solution, AAFA pastes dried quicker, and reached equilibrium faster than OPC paste. AAFA pastes also lost more moisture, but generally exhibited a lower drying shrinkage than OPC at similar RH. Steam curing of AAFA for a longer period (7-day vs. 1 day) stabilized the structure of AAFA binders and lowered the drying shrinkage.
\end{abstract}

\section{INTRODUCTION}

Alkali activated fly ash (AAFA) could serve as an alternative to ordinary Portland cement, OPC, binder for concrete and provide significant environmental and durability benefits [Fernández-Jiménez et al. 2006 and 2008, Provis and Van Deventer 2009]. In order to manufacture AAFA, pulverized coal fly ash is mixed with a concentrated alkaline solution (instead of water), and often heat cured under steam or dry conditions. This results in dissolution of fly ash and formation of a three dimensional sodium aluminosilicate binder (referred to as $\mathrm{N}-\mathrm{A}-\mathrm{S}-\mathrm{H}$ or geopolymer gel). Despite its numerous benefits, one factor that has mitigated a widespread commercialization and industry acceptance of alkali activated concrete is a potential volumetric instability and propensity to shrinkage and cracking in these materials. Large 
shrinkage increases the cracking risk, especially in a restrained condition, and leads to a reduction in mechanical properties and durability of concrete. This, in turn, is affected by the ingress of moisture and damaging ions (e.g., chlorides or sulfates). Limited research has been conducted on the risk and mechanisms of shrinkage in AAFA systems. As such, the objectives of this study are to properly measure drying shrinkage in AAFA binders, and to investigate the effects of critical parameters such as activator composition, steam curing duration, and ambient relative humidity $(\mathrm{RH})$, on the measured drying shrinkage of AAFA binders.

In addition to fly ash composition, properties of the activating solution have been shown to affect the mechanical and microstructural properties of AAFA binders [Provis and Van Deventer 2009]. Three underlying parameters that are commonly used to identify the activator composition are the activator's $\mathrm{pH}$, modulus ( $\mathrm{n}=$ the molar ratio $\left[\mathrm{SiO}_{2}\right] /\left[\mathrm{Na}_{2} \mathrm{O}\right]$ ), and water content [Kazemian et al. 2015]. However, these three parameters are interrelated and knowledge of two out of three is sufficient to identify the activator composition. The $\mathrm{pH}$ highly influences the rate of dissolution and reactivity of fly ash [Iler 1979, Feng et al. 2004, Criado 2008, Kazemian et al. 2015]. The modulus (n) represents the dissolved silicate concentration in the activator, which can readily participate in the formation of geopolymer gel as a result of reaction with $\mathrm{Al}, \mathrm{Na}$ and $\mathrm{Ca}$ dissolved from fly ash [Feng et al. 2004]. Water content or mass percent of water in the activator solution affects the workability and ultimate porosity of the AAFA paste. In addition, heat treatment/curing has a significant impact on the mechanical and microstructural properties of AAFA by acceleration dissolution and precipitation reactions [Van Jaarsveld et al. 2002, Hardjito et al. 2008]. All of these parameters can impact the microstructural properties of the binder and as such, could affect the drying shrinkage [Ma and Ye 2015].

Selected past studies [Fernández-Jiménez et al. 2006, Wallah 2009] have measured the shrinkage of AAFA heat cured in a dry environment. In their research, AAFA specimens were heat-cured at $60^{\circ} \mathrm{C}$ for 24 hours and after curing, placed in an air-dry laboratory environment. Although the reported shrinkage was small, it is likely that a significant portion of the drying shrinkage occurred during the dry heat curing period and as such, was missed by the shrinkage measurement that started after heat curing at $60^{\circ} \mathrm{C}$ for 24 hours. Therefore, care needs to be taken to minimize drying of the specimens during heat curing and before the start of the shrinkage measurements.

\section{EXPERIMENTAL INVESTIGATION}

Raw Materials and Activating Solutions. In this study, the AAFA specimens were prepared by alkali activation of a class F fly ash meeting ASTM C 618-12a requirements. ASTM C150 type I ordinary Portland cement (OPC) was used to prepare a control mixture. Error! Reference source not found. presents the chemical compositions and physical properties of the raw materials utilized. All experiments were performed on paste mixtures, except the compressive strength, which was measured using mortars with identical binder composition as the reference paste mixture. The sand used in the mortars was a manufactured sand with the bulk dry specific gravity of 2.70 and absorption capacity of $0.46 \%$.

Table 1. Oxide compositions of OPC and fly ash powder (mass \%)

\begin{tabular}{|c|c|c|c|c|c|c|c|c|c|c|}
\hline Oxides & $\mathrm{SiO}_{2}$ & $\mathrm{Al}_{2} \mathrm{O}_{3}$ & $\mathrm{CaO}$ & $\mathrm{Fe}_{2} \mathrm{O}_{3}$ & $\mathrm{MgO}$ & $\mathrm{SO}_{3}$ & $\mathrm{Na}_{2} \mathrm{O}_{\text {eq }}$ & LOI & $\begin{array}{l}\text { Sp. } \\
\text { Gr. }\end{array}$ & $\begin{array}{c}\text { \%Passing 45 } \mu \mathrm{m} \\
\text { (No. 325) }\end{array}$ \\
\hline OPC & 19.25 & 4.65 & 62.30 & 3.52 & 4.08 & 2.71 & 0.51 & 2.51 & 3.15 & 98.40 \\
\hline Fly & 46.69 & 22.44 & 4.99 & 19.43 & 1.04 & 0.76 & 1.74 & 2.00 & 2.64 & $81 \%$ \\
\hline
\end{tabular}


AAFA mixtures were prepared using laboratory-made sodium silicate activators with varying compositions (Table 1). To prepare these activator solutions, a commercially available sodium silicate solution was mixed at different proportions with an either 2 or 10 molar sodium hydroxide $(\mathrm{NaOH})$ solution. The commercial aqueous sodium silicate solution consisted of $18.4 \% \mathrm{Na}_{2} \mathrm{O}, 28.4 \% \mathrm{SiO}_{2}$ and $53.2 \% \mathrm{H}_{2} \mathrm{O}$ with $\mathrm{pH}=13.7$ and specific gravity of 1.60 , at $20^{\circ} \mathrm{C}$ and the silicate modulus $\mathrm{n}=1.60$ ). As it is displayed in Table 1, the $\mathrm{pH}$ of the activating solutions fell in the range 14.1 to 15.0 , while the modulus (n) varied between 0.00 and 1.38 .

\section{Table 1. Activating solution properties for each AAFA paste}

\begin{tabular}{ccccc}
\hline Mixture & $\mathrm{pH}$ & $\begin{array}{c}\mathrm{n}= \\
\left(\mathrm{SiO}_{2} / \mathrm{Na}_{2} \mathrm{O}\right) \\
\text { molar-based }\end{array}$ & $\begin{array}{c}\text { Density } \\
(\mathrm{g} / \mathrm{cc})\end{array}$ & $\begin{array}{c}\text { Water } \\
\text { mass } \\
(\%)\end{array}$ \\
\hline \hline $\mathrm{M} 1$ & 14.1 & 1.38 & 1.36 & 66.2 \\
\hline $\mathrm{M} 2$ & 15.0 & 0.00 & 1.21 & 67.0 \\
\hline $\mathrm{M} 3$ & 14.8 & 0.67 & 1.38 & 60.1 \\
\hline $\mathrm{M} 4$ & 14.6 & 0.94 & 1.45 & 57.8 \\
\hline
\end{tabular}

Table 2. Curing regime for analyzed mixtures within the first 7 days of curing

\begin{tabular}{|c|c|c|c|c|c|c|c|}
\hline \multirow{2}{*}{ Mixture } & \multicolumn{7}{|c|}{ Curing days } \\
\hline & 1 & 2 & 3 & 4 & 5 & 6 & 7 \\
\hline & \\
\hline M1 & S* & \multicolumn{3}{|c|}{$\mathrm{M}^{* *}$} & & & \\
\hline M2 & $S$ & \multicolumn{6}{|c|}{$\mathrm{M}$} \\
\hline M3 & $S$ & \multicolumn{6}{|c|}{$\mathrm{M}$} \\
\hline M4 & $S$ & \multicolumn{6}{|c|}{$\mathrm{M}$} \\
\hline $\mathrm{OPC}$ & \multicolumn{7}{|c|}{$\mathrm{M}$} \\
\hline & \multicolumn{7}{|c|}{ Phase II } \\
\hline M4-7D-S & \multicolumn{7}{|c|}{$\mathrm{S}$} \\
\hline OPC-1D-S & \multicolumn{7}{|c|}{$\mathrm{M}$} \\
\hline OPC-7D-S & \multicolumn{7}{|c|}{ S } \\
\hline
\end{tabular}

Mixture Design. Four different AAFA paste mixtures were designed and tested in this work. All pastes were mixed following ASTM C 305-11. The liquid (activating solution or water) to solid (fly ash or OPC) volumetric ratio $(\mathrm{L} / \mathrm{S})_{\mathrm{vol}}$ for all pastes was maintained at 0.95 , resulting in the same initial porosity of $48.7 \%$ for all pastes. For the OPC mixture, the chosen $(\mathrm{L} / \mathrm{S})_{\mathrm{vol}}$ was equivalent to $\mathrm{w} / \mathrm{c}=0.30$. Mortar mixtures contained $50 \%$ volume fraction of sand.

Test Methods. Drying shrinkage of the paste mixture was measured using "minibar" prisms $(1.27 \times 1.27$ $\times 12.7 \mathrm{~cm}$ ). These thin specimens were used in order to reach equilibrium faster (i.e., had higher drying rate). After mixing and casting, different curing regimes were applied for AAFA and OPC mixtures, according to Table 2. In Phase I of this work, AAFA mixtures were steam cured $\left(100 \% \mathrm{RH}, 60^{\circ} \mathrm{C}\right)$ for the first 24 hours to ensure proper strength gain, followed by 6 days of moist curing. The control OPC mixture was moist cured for 7 days. Phase II evaluated the effect of steam curing duration on shrinkage of AAFA and OPC mixtures. In this phase, one AAFA mixture (M4) was steam cured for 7 days (M4-7DS). Two additional OPC mixtures were prepared and steam cured for 1 day (OPC-1D-S) or 7 days (OPC7D-S). In both phases, after curing, the minibar specimens were placed under nitrogen purge inside four environmental chambers that were set at four different relative humidities (RH=30\%, 50\%, $70 \%$ or $85 \%$ ). All of the specimens (both in Phase 1 and Phase 2) were demolded after 24 hours and their reference length was recorded. The length change of minibars was measured using a digital comparator with an accuracy of $0.0025 \mathrm{~mm}$. Shrinkage and mass loss of minibars were monitored regularly over time until the age of 70 days. In addition, mercury intrusion porosimetry (MIP) was used to determine the porosity and pore size distribution of different paste mixtures at the age of 7 days. For MIP test, samples were 
prepared by solvent exchange after one week of curing by submerging them into a $70 \%$ isopropyl alcohol solvent for drying within 10 days. The solvent was replaced by fresh one every other day. Compressive strength was also measured according to ASTM C109M-11b on equivalent mortar cubes.

\section{RESULTS AND DISCUSSIONS}

Pore Size Distribution and Compressive Strength. Although the focus of this study was shrinkage measurements, to provide a measure of pore structure and strength development of AAFA and OPC mixtures, the MIP results are presented first. Error! Reference source not found. shows the pore size distribution of different mixtures after 7 days of curing. In addition, Table 3 reports the values of total porosity and pore size distribution for each mixture (D10, D50 and D90). In this table, pore size refers to the diameter. The results indicate that mixture M4 (activator with intermediate $\mathrm{n}$ and $\mathrm{pH}$ and lowest water content) had the lowest porosity and smallest median pore size among the AAFA pastes. On the other hand, mixture M2 (activator with highest $\mathrm{pH}$ and no silica) resulted in a significantly larger pore size comparing with the other AAFA mixtures, although the porosity of M1, M2, and M3 were comparable. This is in agreement with previous studies [Davidovits 1999], which suggested that added dissolved silica in the activator participates in the geopolymerization products (N-A-S-H gel), and results in a denser microstructure. The control OPC specimen had the lowest porosity, but the median pore size was comparable with M4. Increasing the duration of steam curing from 1 day to 7 days had little effect on pore structure of M4. Steam cured OPC showed higher porosity at 7 days comparing with the moist cured OPC paste.

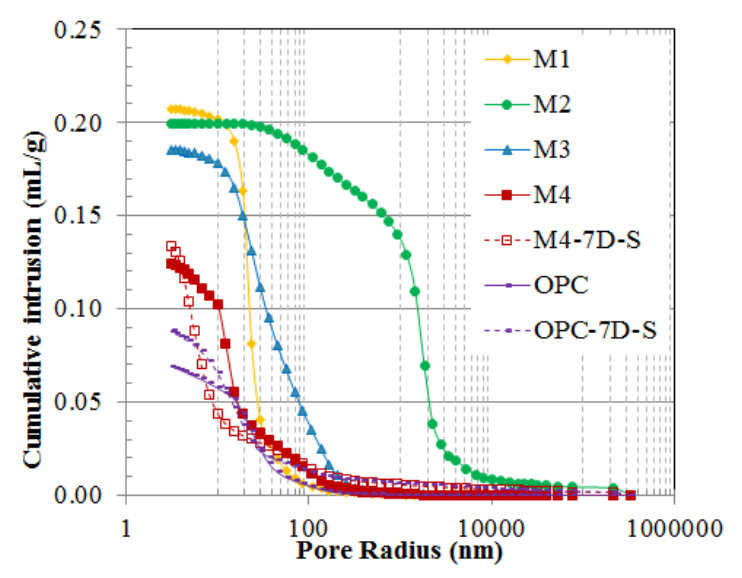

Figure 1. Pore size distribution measured by MIP after 7 days of curing

Table 3. MIP results for analyzed mixtures after 7 days of curing

\begin{tabular}{|c|c|c|c|c|}
\hline Mixture & Total & \multicolumn{3}{|c|}{ Pore size distribution (nm) } \\
\cline { 3 - 5 } & $\begin{array}{c}\text { Porosity } \\
(\%)\end{array}$ & D10 & D50 & D90 \\
\hline M1 & 34.0 & 16 & 23 & 43 \\
\hline M2 & 31.9 & 110 & 1470 & 4060 \\
\hline M3 & 30.1 & 15 & 40 & 160 \\
\hline M4 & 23.9 & 7 & 12 & 102 \\
\hline OPC & 13.7 & 7 & 24 & 82 \\
\hline M4-7D-S & 25.1 & 4 & 7 & 107 \\
\hline
\end{tabular}




\begin{tabular}{|l|l|l|l|l|}
\hline OPC-7D-S & 16.9 & 6 & 15 & 260 \\
\hline
\end{tabular}

Figure 1 demonstrates the compressive strength results of Phase I AAFA and OPC mortars. For each measurement, three mortar cubes were tested and the results were averaged. The range of maximum and minimum of these results are shown in each graph. After the first week of curing (according to Phase I Table 2), all AAFA and OPC mortar specimens were moved into an environmental chamber (100\% $\mathrm{RH}$, $23 \pm 0.5^{\circ} \mathrm{C}$ ) until the age of testing. The control OPC mixture demonstrated the greatest compressive strength due to its low w/c ratio. Among AAFA mortars, M4 showed the highest compressive strength, while M2 exhibited the lowest compressive strength. These results are in good agreement with MIP results reported above. The majority of strength development in AAFA mixtures generally happened within the $1^{\text {st }}$ day steam curing period, while OPC mortars showed considerable strength gain over time. This agrees with the results of Kazemian et al. (2015) who showed also that the majority of strength gain for AAFA binders occur during steam curing period and subsequent moist curing may not significantly improve the strength. Kazemian et al. (2015) also reported that prolonging the steam curing (up to 3 or 7 days) for AAFA could substantially improve the compressive strength due to the higher dissolution of unreacted fly ash at high temperature. As such, AAFA specimens in Phase II of this research (Table 2) are likely to have higher compressive strength compared to Phase I.

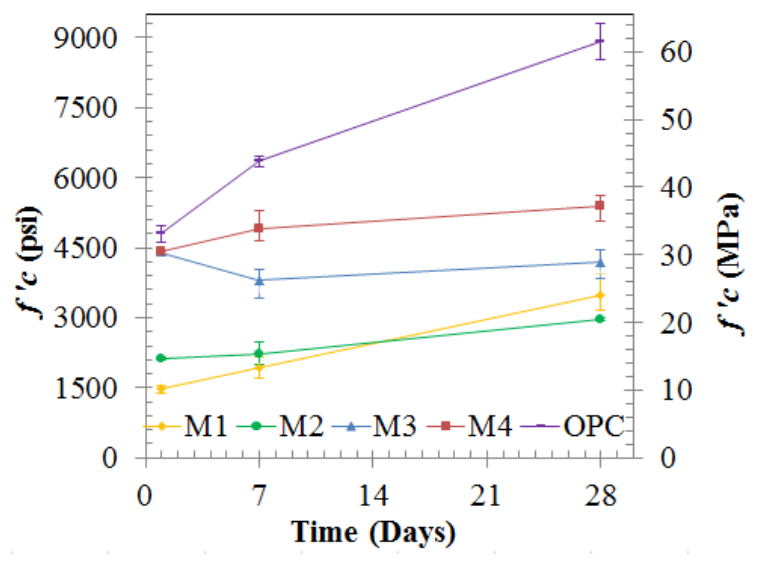

\section{Figure 1. Compressive strength development of AAFA and OPC mortars as a function of age}

\section{Drying Shrinkage}

Phase I shrinkage results. Figure 2 and

Figure 3 show drying shrinkage and mass loss of the AAFA and OPC pastes mixtures (Phase I) at different $\mathrm{RH}$ values. The results up to 7 days reflect the volume and mass change during the curing period. All pastes gained mass during curing and all, but one (M2), expanded (up to $500 \mu \varepsilon$ ) during curing. After initiation of drying and for $\mathrm{RH}=70 \%$ or below, all AAFA mixtures showed shrinkage values that were approximately $65 \%$ or lower than the shrinkage of OPC paste. At $\mathrm{RH}=85 \%$, shrinkage of OPC is comparable to that of AAFA. Interestingly, AAFA pastes lost significantly more mass and reached equilibrium faster than the OPC mixture. This is in agreement with the higher porosity of the AAFA pastes (Table 4). The OPC paste did not lose any mass at $\mathrm{RH}=85 \%$, suggesting that its internal $\mathrm{RH}$ due to 
self-desiccation was likely close to $85 \%$ (note the low w/c=0.30 for the OPC paste). Among the different AAFA mixtures, M4 (activator with intermediate $\mathrm{n}$ and $\mathrm{pH}$ and lowest water content, resulting in AAFA paste with highest strength and smallest porosity and pore size) showed the largest drying shrinkage and the lowest mass loss.
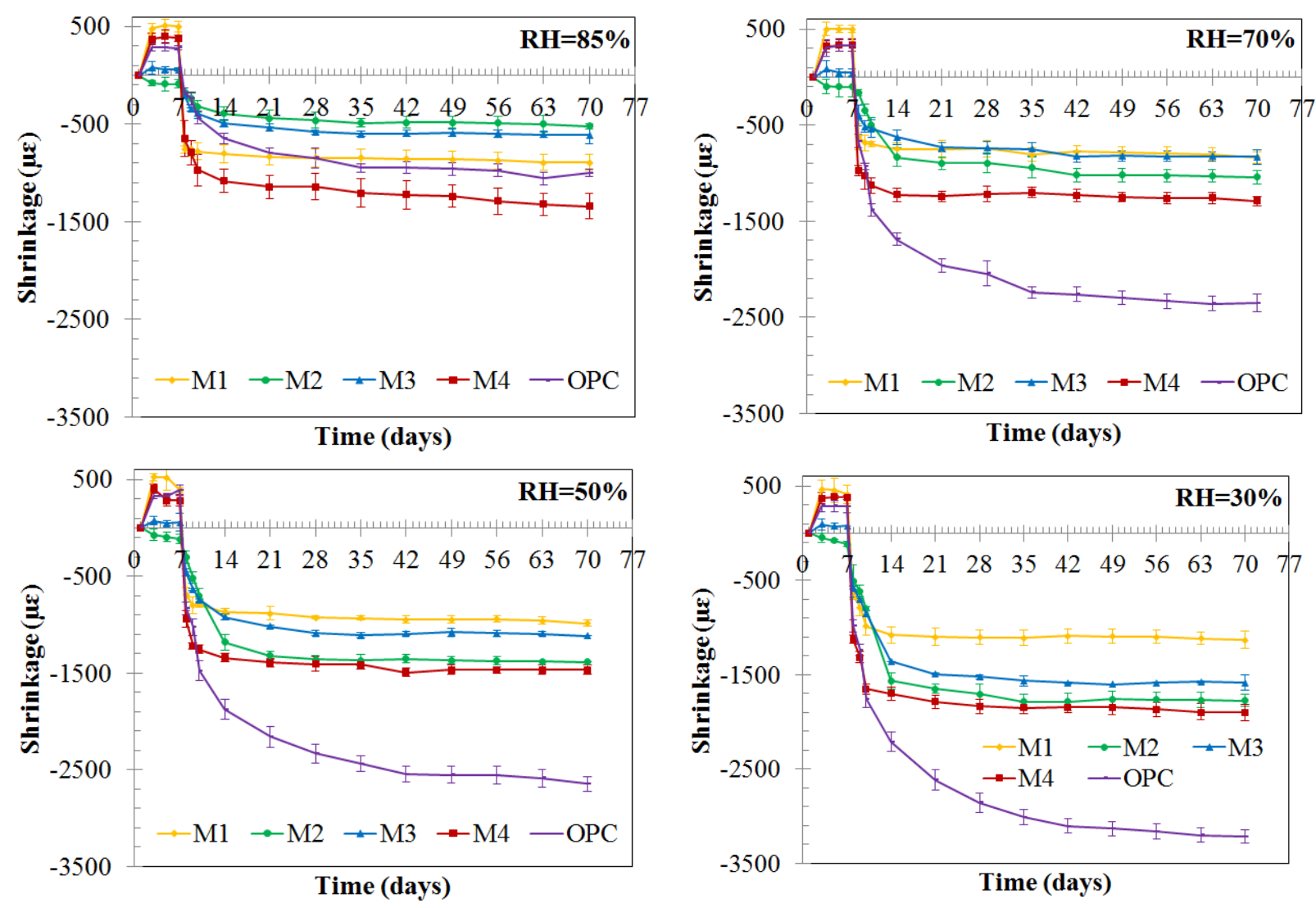

Figure 2. Drying shrinkage (Phase I) of AAFA and OPC pastes as a function of age for different RHs (reference point is day 1; time of demolding)

Figure 4 displays the results of the equilibrium drying shrinkage and mass loss of all Phase I mixtures as a function of RH. These results correspond with the age of 70 days, or 9 weeks of drying. At this age, all mass loss data for AAFA pastes have plateaued (see Figure 4), and the majority of AAFA mixtures have also reached their equilibrium shrinkage strain. It is interesting, however, to note that in Figure 3 at $\mathrm{RH}=85 \%$ both mixtures M4 and to a lesser extent M1 show a small continued increase in shrinkage with time, despite the fact that the corresponding mass loss (Figure 4) has plateaued. This suggests that these mixtures are experiencing drying-induced creep at $\mathrm{RH}=85 \%$. The OPC mixture at 70 days is approaching but has not yet reached equilibrium.

According to

Figure $4 \mathrm{~b}$, the mass loss of all pastes increases monotonically with reduced $\mathrm{RH}$. The mixtures M1 and M4 showed a similar mass loss for $\mathrm{RH}=50 \%$ and $30 \%$. Shrinkage of OPC ( 
Figure 4a) increased monotonically with reduced RH and showed a bilinear behavior (i.e., higher rate of shrinkage vs. RH for RH>70\%). This is consistent with past studies on OPC shrinkage [Hansen 1987, Weiss et al. 2008], and has been suggested to be due to a change in shrinkage mechanisms from capillary tension to other mechanisms such as Gibbs-Bangham shrinkage or loss of disjoining pressure. For AAFA mixtures M2 and M3, shrinkage increased fairly linearly with RH drop. Mixtures M1 and M4, on the other hand, shrank rapidly until $\mathrm{RH}=85 \%$, but their further shrinkage is much smaller for $\mathrm{RH}<85 \%$; although they continue to lose mass for RH $<85 \%$. This may be caused by changing in the governing shrinkage mechanisms at $\mathrm{RH}=85 \%$ versus $\mathrm{RH}=70 \%$ and lower.
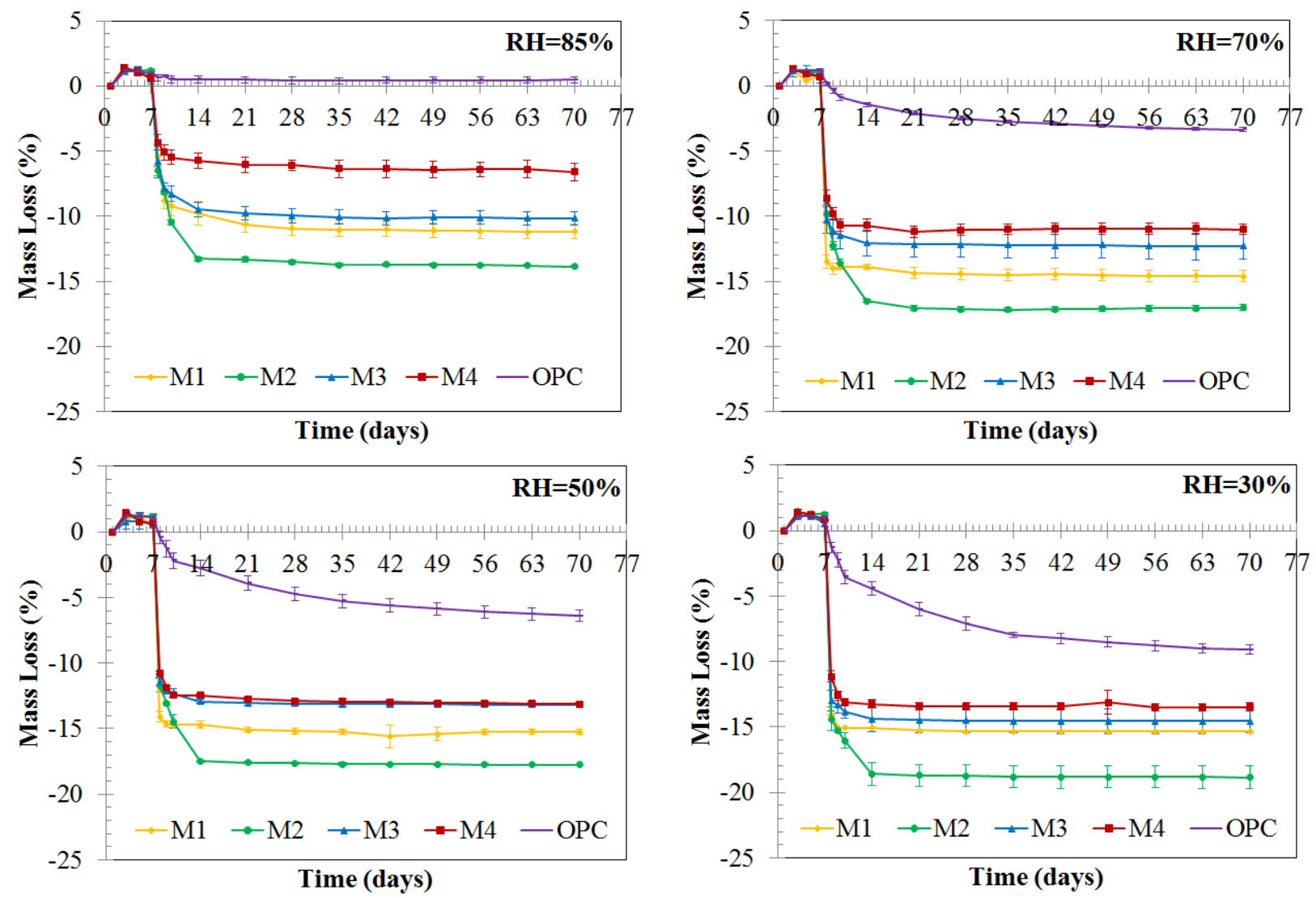

\section{Figure 3. Mass loss (Phase I) of AAFA and OPC pastes as a function of age for different RHs (reference point is day 1 ; time of demolding)}

Past research on shrinkage of OPC suggests that the dominant shrinkage mechanism at high RH is the capillary stress [Hansen 1987]. According to this mechanism, the Mackenzie-Bentz's equation (1) [Bentz 1998 ] relates the linear elastic shrinkage strain of the paste $\left(\varepsilon_{\mathrm{p}}\right)$ to the capillary stress that develops $\left(\sigma_{\text {cap }}\right)$ as a result of drying-induced formation of liquid-air menisci inside the pores. The other parameters in equation (1) represent the degree of saturation of the paste $(S)$, the bulk modulus of the paste $(K)$, and the bulk modulus of the solid skeleton $\left(\mathrm{K}_{\mathrm{s}}\right)$. A significant limitation of this equation is that it assumes the material behaves linearly elastic. 


$$
\varepsilon_{p}=\frac{S}{3} \sigma_{c a p}\left[\frac{1}{K}-\frac{1}{K_{S}}\right]
$$

Kelvin-Laplace equation (2) can provide the capillary stress applied to the pore walls by the liquid-air meniscus as follows [Radlinska et al. 2008]:

$$
\sigma_{\text {cap }}=-\frac{4 \gamma \cos \theta}{\mathrm{d}}=\frac{R T \ln (R H)}{V_{m}}
$$

Where $\sigma_{\text {cap }}$ is the capillary stress, $\mathrm{d}$ is the meniscus diameter, which is equal to the diameter of the largest pore that remains filled with pore solution, and $\theta$ is the solid-liquid contact angle (assumed to be zero). $\mathrm{R}$ is the universal gas constant $(8.314 \mathrm{~J} / \mathrm{mol} \cdot \mathrm{K}), \mathrm{T}\left({ }^{\circ} \mathrm{K}\right)$ is the temperature, $\mathrm{RH}$ is the internal relative humidity (similar to ambient $\mathrm{RH}$ at equilibrium), and $\mathrm{V}_{\mathrm{m}}$ is the molar volume of pore solution. Equation (2) also correlates the RH and menisci radius (i.e., largest pore size that remain saturated). Assuming $\gamma=0.072 \mathrm{~N} / \mathrm{m}$ and $\mathrm{V}_{\mathrm{m}} \approx 18 \times 10^{-6} \mathrm{~m}^{3} / \mathrm{mol}$, Equation (2) suggests that at $\mathrm{RH}=85 \%$, pores larger than $13 \mathrm{~nm}$ have dried out and at $\mathrm{RH}=70 \%$, pores larger than $5.9 \mathrm{~nm}$ are dry. The equation and the capillary stress mechanism become invalid for smaller RH $<70 \%$ since smaller pores cannot maintain a liquid-air meniscus [Weiss et al. 2008].

For thin specimens exposed to drying, Equation (2) also suggests that $\sigma_{\text {cap }}$ is related to the ambient RH and could be independent of $d$. However, pore size distribution can make its impact in determining the saturation factor (S) in Equation (1). Looking back at Figure 5 and the MIP results (Table 4) shows that at $\mathrm{RH}=85 \%$ where the capillary stress mechanism was in effect, the pastes M4 and OPC had retained a large portion of their capillary water, resulting in shrinkage-inducing capillary stresses. At the same $\mathrm{RH}=85 \%$, pastes M1, M2 and M3 were practically dry of capillary water due to their coarser porosity. Based on Figure $5 \mathrm{~b}$, at $\mathrm{RH}=70 \%$, while the OPC paste still maintained a fairly high saturation level, all AAFA pastes had dried, and this may explain their significantly lower shrinkage in comparison with OPC (Figure 5a). Below $\mathrm{RH}=70 \%$, the capillary stress seized to exist and all paste mixtures shrank at a similar rate with respect to $\mathrm{RH}$.

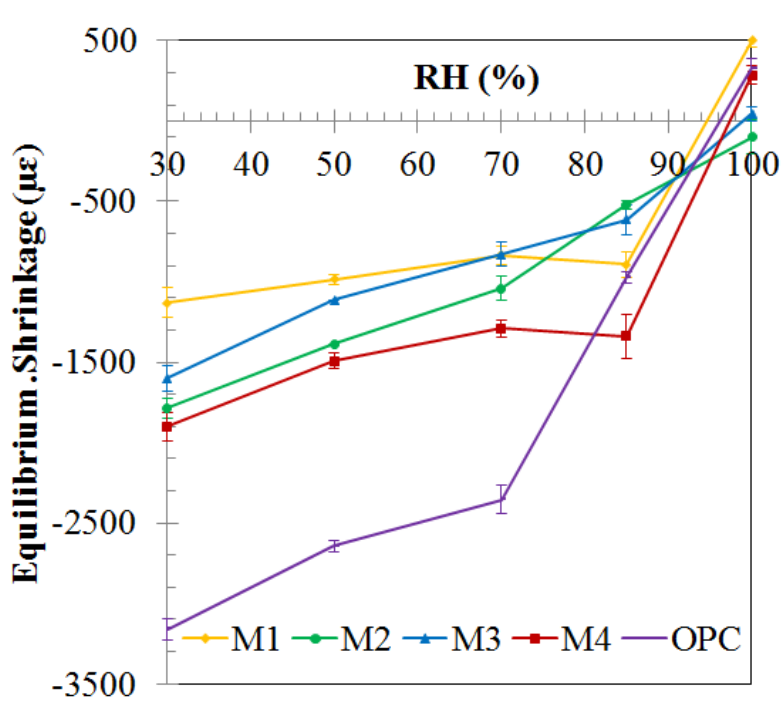

(a)

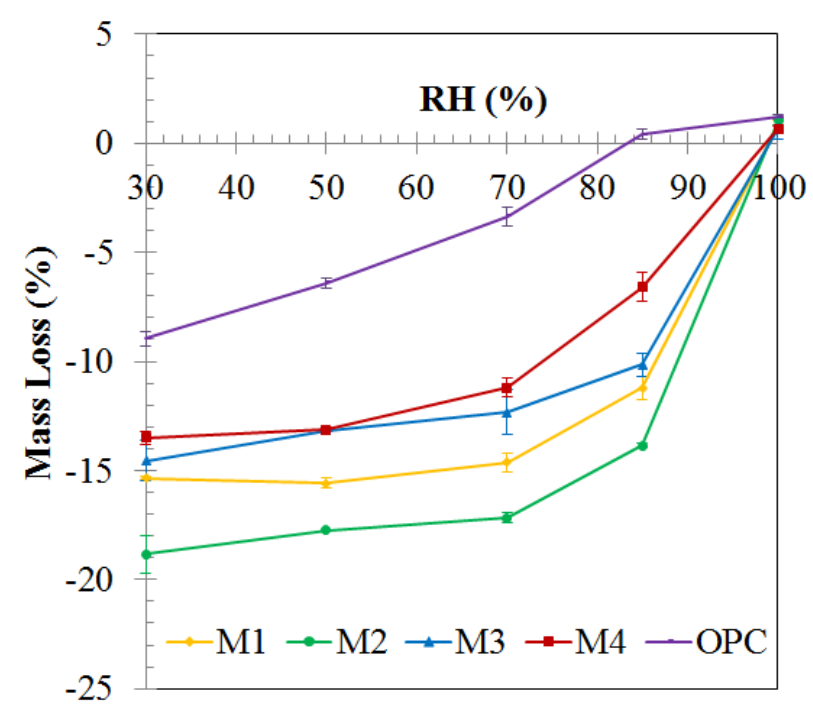

(b) 
Figure 4. Drying shrinkage and mass loss versus RH for Phase I paste minibars (reference point is day 1: time of demolding)

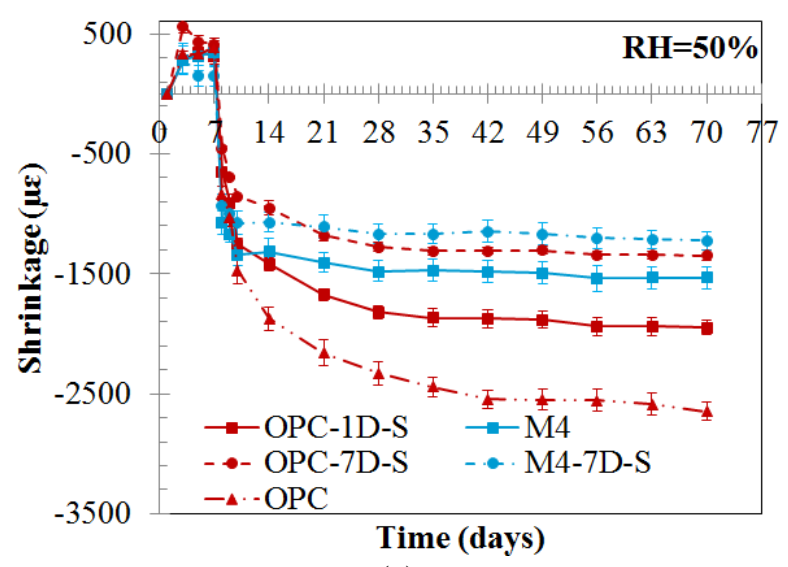

(a)

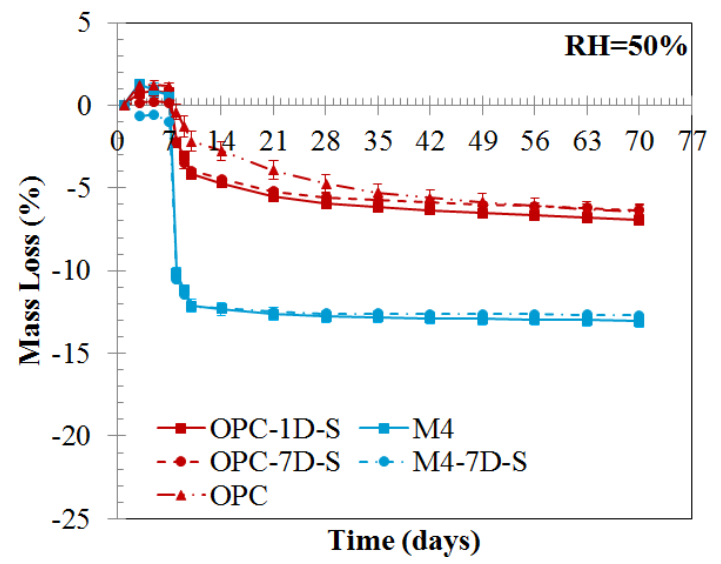

(b)

Figure 5. Drying shrinkage and mass loss of M4 and OPC pastes at different steam curing durations under nitrogen purge at $\mathbf{R H}=50 \%$ (reference point is day 1: time of demolding)

*Note:-1D-S: 1 day steam cured and then 6 days moist cured -7D-S: 7 days steam cured

Phase II shrinkage results. Figure 5 presents the results of drying shrinkage and mass loss of M4 and OPC pastes which were prepared using different curing conditions, and then dried under the nitrogen purge at $\mathrm{RH}=50 \%$ after 7 days of curing. For the paste M4, extended steam curing ( 7 days instead of 1 day) reduced drying shrinkage (by $22 \%$ ) but did not significantly impact pore size distribution or the mass loss results. As such, it is possible that the reduced shrinkage was primarily due to stiffening of the matrix as a result of extended heat curing. For the OPC pastes, steam curing resulted in slightly higher porosity (Figure 1) and larger mass loss (Figure 6). However, drying shrinkage was reduced by up to $30 \%$ and $50 \%$ when the 7- day moist cured OPC is compared with 1 day or 7-day steam cured OPC, respectively. This is also likely due to maturing and stiffening of the matrix as a result of steam curing [Skalny and Odler 1972, Bakharev et al. 1999].

\section{CONCLUSION}

The length and mass change of four AAFA pastes and a control OPC with similar initial porosity were monitored within 9 weeks of drying following 1-week curing. The main findings are presented below:

- The properties of activating solution $(\mathrm{n}$ and $\mathrm{pH}$ ) play an important role in the mechanical and microstructural properties of AAFA binders. The AAFA paste M4 made with activator with intermediate $\mathrm{n}$ and $\mathrm{pH}$ and lowest water content resulted in the lowest porosity and median pore size and the largest compressive strength. On the other hand, paste M2 activated with highest $\mathrm{pH}$ and no silica resulted in a high porosity and coarse pore size matrix with low compressive strength.

- The pore structure, in turn, impacts the drying shrinkage of all pastes, primarily through influencing the saturation factor (S). In addition, stiffness of the paste matrix also impacts shrinkage.

- AAFA pastes dried and reached equilibrium faster than OPC, and lost more moisture. These were all in agreement with their higher porosity. 
- AAFA pastes shrank in a similar manner to OPC until $\mathrm{RH}=85 \%$. Between $\mathrm{RH}=85 \%$ and $70 \%$, AAFA pastes shrank considerably less than OPC, most likely due to their significantly lower saturation factor. Below $\mathrm{RH}=70 \%$, all AAFA and OPC mixtures shrank at similar rate.

- The steam curing process (and longer periods of steam curing) for OPC and AAFA pastes resulted in considerable decrease in drying shrinkage, without significantly changing the drying mass loss of specimens. The porosity of steam cured binder increased slightly, although their pore size distribution was largely unaffected. The reduced shrinkage is most likely due to stiffening of the solid matrix by heat curing.

\section{ACKNOWLEDGEMENTS}

The authors gratefully acknowledge the financial support from the National Science Foundation (NSF) under Award CMMI \#1265789. Any opinions, findings and conclusions or recommendations expressed in this material are those of the authors and do not necessarily reflect the views of the National Science Foundation. The authors appreciate Headwaters Resources for donating the fly ash. All tests were performed at the Civil Infrastructure Testing and Evaluation Laboratory (CITEL) and the Materials Research Institute (MRI) of Penn State.

\section{REFERENCES}

Bakharev, T., Sanjayan, J. G., Cheng, Y. B. (1999). "Effect of elevated temperature curing on properties of alkali-activated slag concrete." Cement and Concrete Research, 29, 1619-1625.

Bentz, D. P., Garboczi, E. J., Quenard, D. A. (1998) "Modeling drying shrinkage in reconstructed porous materials: Application to porous Vycor glass." Modeling and Simulation in Materials Science and Engineering, 6, 211-36.

Criado, M. Fernandez-Jimenez, A., Palomo, A., Sobrados, I., Sanz, J. (2008). "Effect of the SiO2/Na2O ratio on the alkali activation of fly ash. Part II: Si-29 MAS-NMR survey." Microporous Mesoporous Mater, 109, 525-534.

Davidovits, J. (1999). "Chemistry of geopolymeric systems. Terminology. Geopolymer.” 99 International Conference; France.

Feng, D., Tan, H., Van Deventer, J. S. J. (2004). "Ultrasound enhanced geopolymerisation." Journal of Materials Science, 39, 571-80.

Fernández-Jiménez, A. M., Palomo, A., Lopez-Hombrados, C. (2006). "Engineering properties of alkaliactivated fly ash concrete." ACI Material Journal, 103, 106-112.

Fernández-Jiménez, A., Palomo A., Pastor, J. Y., Martín, A.(2008). "New cementitious materials based on alkali-activated fly ash: performance at high temperatures." Journal of the American Ceramic Society, 91, 3308-3314.

Hansen, W. (1987). "Drying shrinkage mechanisms in Portland cement paste." Journal of the American Ceramic Society, 70, 323-328.

Hardjito, D., Cheak, C. C., Lee, C.H. (2008). "Strength and setting times of low calcium fly ash-based geopolymer mortar." Modern Applied Science, 2(4), 9-18.

Iler, R. K. (1979). "The chemistry of silica: solubility, polymerization, colloid and surface properties, and biochemistry." New York: Wiley. 
Kazemian, A., Gholizadeh-Vayghan, A., Rajabipour, F. (2015). "Quantitative assessment of parameters that affect strength development in alkali activated fly ash binders." Construction and Building Material, http://dx.doi.org/10.1016/j.conbuildmat.2015.05.078

Ma, Y. and Ye, G. (2015). "The shrinkage of alkali activated fly ash." Cement and Concrete Research, $68,75-82$.

Provis, J. L., Van Deventer, J. S. J. (2009). "Geopolymers: structure, processing, properties and industrial applications." Woodhead Publishing and CRC Press.

Radlińska, A., Rajabipour, F., Bucher, B., Henkensiefken, R., Sant, G., Weiss, J. (2008). "Shrinkage mitigation strategies in cementitious systems: a closer look at differences in sealed and unsealed behavior." Transportation Research Record, No. 2070, 59-67.

Skalny, J., Odler, I. (1972). "Pore structure of calcium silicates." Cement and Concrete Research, 2(4), 87-400.

Van Jaarsveld, J. G. S., Lukey, G.C. (2002). "The effect of composition and temperature on the properties of fly ash-and kaolinite-based geopolymers." Chemical Engineering Journal, 89(1-3), 63-73.

Wallah, S. E. (2009), "Drying Shrinkage of Heat-Cured Fly Ash-Based Geopolymer Concrete", Modern applied science, 12(3), 14-21.

Weiss, J., Lura, P., Rajabipour F., Sant, G. (2008). "Performance of shrinkage reducing admixtures at different humidities at early ages.” ACI Materials Journal, 105(5), 478-486. 